\title{
Interactive comment on "Astronomical Calibration of the Ypresian Time Scale: Implications for Seafloor Spreading Rates and the Chaotic Behaviour of the Solar System?' by Thomas Westerhold et al.
}

Thomas Westerhold et al.

twesterhold@marum.de

Received and published: 24 March 2017

please see the supplement to this comment for reply to reviewer Stephen Meyers

Please also note the supplement to this comment:

http://www.clim-past-discuss.net/cp-2017-15/cp-2017-15-AC2-supplement.pdf 